\section{Higher Sensitivity of Denaturing Gradient Gel Electrophoresis than Sequencing in the Detec- tion of Mutations in DNA from Tumor Samples}

\section{BioTechniques 24:72-76 (January 1998)}

A wide variety of human tumors has been shown to be associated with mutations in tumor-suppressor genes or oncogenes. Traditionally, these mutations have been studied by constant denaturing gel electrophoresis (CDGE), denaturing gradient gel electrophoresis (DGGE) or single-strand conformation polymorphism (SSCP). It has been suggested $(8,11)$ that DGGE is the most sensitive and easy to use.

In our laboratory, DGGE is routinely used to screen for mutations in exons 5 to 8 of p53 because these conserved regions tend to accumulate mutations. However, no mutation could be detected by sequencing in some of the DGGE-positive samples. Moreover, we found these false-negatives using DNA from tumor tissue but not from peripheral blood cells from members of families with reported history of breast cancer (10). These observations suggested to us that sequencing could have a lower sensitivity than DGGE to detect mutations from tumor samples. Indeed, this was consistent with the observations made by others using CDGE and DGGE (2) and with those obtained by Newmark et al. with exon $\mathrm{G}$ of the androgen-receptor gene (12) and Beck et al. (3) with the p53 gene.

Moyret et al. discussed the relative sensitivities of DGGE and SSCP. According to these authors, mutation detection by sequencing of positive samples that were positive by either method was not always easy, and they suggest that a low proportion of mutated DNA could be a cause (11). On theoretical considerations, Bosari and Viale (6) have suggested that mutations can be detected by sequencing when the proportion of wildtype alleles does not exceed two thirds of the material to be analyzed. Loda (9) suggested that at least $20 \%$ of the cells analyzed should carry the mutation.
We have determined more accurately the proportion of mutant DNA necessary to detect a single point mutation using both DGGE and direct sequencing of polymerase chain reaction (PCR) products. The approach followed has been to compare the sensitivity of DGGE and sequencing in samples with the same amount of total DNA but containing increasing proportions of a DNA carrying a previously defined mutation.

As a source of mutant DNA, we used peripheral blood of a patient with a family history of breast cancer. These cells are heterozygous for a neutral polymorphism (CGA) and were verified by direct sequencing of a PCR product. Normal DNA (wild-type) was extracted from peripheral blood of a donor without the polymorphism, and its normal sequence was verified by the same methods. Samples of the mutant and the wild-type DNA were analyzed simultaneously to avoid sample-tosample variations.

DNA was extracted by conventional methods. For PCR, approximately $1 \mu \mathrm{g}$ of each DNA was amplified as previously described (8). The primers used were located on introns 4 and 6 , respectively, and the resulting fragment of 506 bp encompasses exons 5 to 6 .

PCR products were purified using the Sephaglas ${ }^{\mathrm{TM}}$ BandPrep Kit (Pharmacia Biotech, Uppsala, Sweden) after excising the band from a $1.8 \%$ agarose gel. To prepare a mixture containing known relative proportions of mutant and wild-type DNA, serial dilutions of the purified PCR product from the heterozygous donor were electrophoresed and stained with ethidium bromide, and pictures were analyzed by densitometry. The areas of the bands of the mentioned dilutions were plotted, and the regression line obtained $\left(\mathrm{r}^{2}=0.98, P\right.$ $<0.01$ ) was used to calculate the relative concentration of wild-type products run in the same gel. PCR product from the heterozygous donor was used as the 50\% mutant DNA. Samples containing decreasing relative proportions of mutant DNA $(40 \%, 35 \%, 30 \%, 25 \%$, $20 \%, 15 \%$ and $10 \%$ ) were prepared by mixing with wild-type DNA. These samples were analyzed as described below. DGGE was performed on a $6.5 \%$ acrylamide/polyacrylamide gel $(16 \mathrm{~cm}$ long) with a denaturing gradient of $30 \%$ to $80 \%$ urea. Each of the above samples $(20 \mu \mathrm{L})$ was run simultaneously at $160 \mathrm{~V}$ for $3.5 \mathrm{~h}$ at a constant temperature of $60^{\circ} \mathrm{C}$ (2) and stained in 1 $\mu \mathrm{g} / \mathrm{mL}$ ethidium bromide in TAE buffer (40 mM Tris, $20 \mathrm{mM}$ sodium acetate, 1 mM EDTA, pH 7.4). The two PCR products $(20 \mu \mathrm{L}$ each) that were included as controls were the wild-type and another mutant control that was heterozygous for the same polymorphism.

Sequencing was performed using the Thermo Sequenase ${ }^{\mathrm{TM}}$ Cycle Sequencing Kit following the manufacturer's instructions (Amersham International plc, Bucks, England, UK), with the reverse primer previously used for PCR and labeling with $[\alpha-33 \mathrm{P}] \mathrm{dATP}$.

Figure 1 shows the DGGE pattern of eight mutant/wild-type DNA mixtures

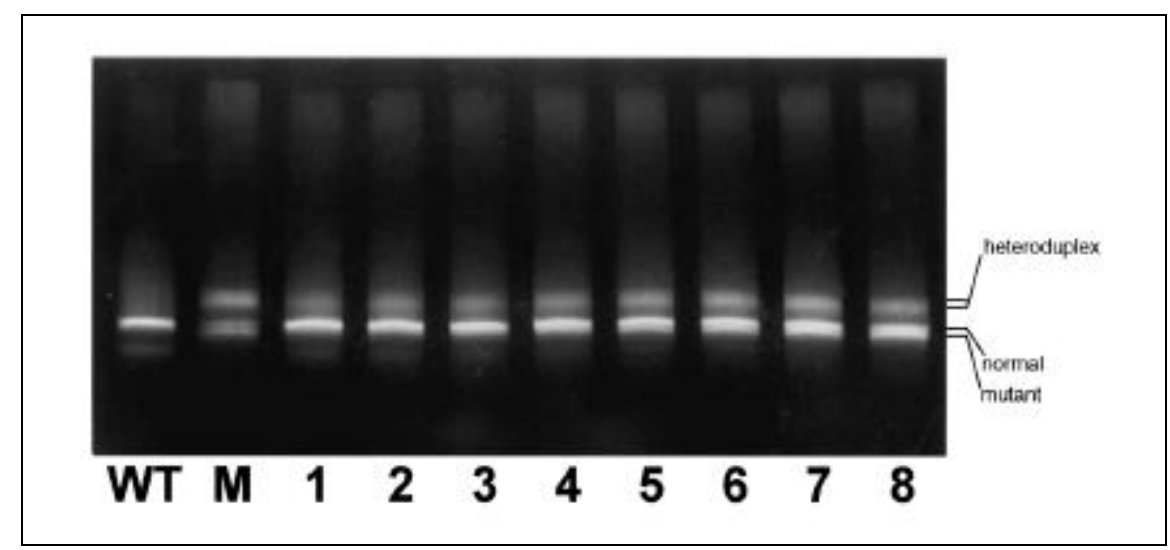

Figure 1. DGGE of exon 6 of the p53 gene. WT: wild-type control DNA; M: mutant control DNA; lanes 1-8: different proportions of mutant and wild-type DNA; lane 1: 10\% of mutant DNA; lane 2: 15\% of mutant DNA; lane 3: $20 \%$ of mutant DNA; lane $4: 25 \%$ of mutant DNA; lane $5: 30 \%$ of mutant DNA; lane 6: $35 \%$ of mutant DNA; lane 7: $40 \%$ of mutant DNA; lane 8: $50 \%$ of mutant DNA. 
(lanes 1-8) as well as the two controls. A well-defined band shift comparable to the positive mutant control (lane M) was detected in all eight mixtures, showing that the mutation could be detected by DGGE in any sample containing at least $10 \%$ of mutant DNA. Moreover, although the band corresponding to the mutant homozygous DNA suffers a gradual decrease of intensity related to the decreasing quantity of mutant DNA, it could still be detected in the mixture containing only $10 \%$ of mutant DNA.

The sequencing autoradiogram of the same eight samples is shown in Figure 2 . The mutation can be clearly detected in sample 8 (50\% mutated DNA). However, mutations could not be objectively assessed when examining the samples containing less mutant DNA. Moreover, the band corresponding to the mutation in samples with a low proportion of mutant DNA is hardly distinguishable from the background bands that usually appear in sequencing gels of PCR products (Figure 2, bands marked with “*”). Since previous knowledge of the presence of the mutation might bias its interpretation, a blind trial was performed with several members of our Biochemistry and Molecular Biology Departments. They read the sequences starting from lane 1, corresponding to the lowest proportion of mutant DNA. In all cases, they were unable to correctly assess the presence of the mutation in samples containing less than 35\%-40\% mutant DNA (lanes 6 and 7, respectively).

DGGE and CDGE are successfully

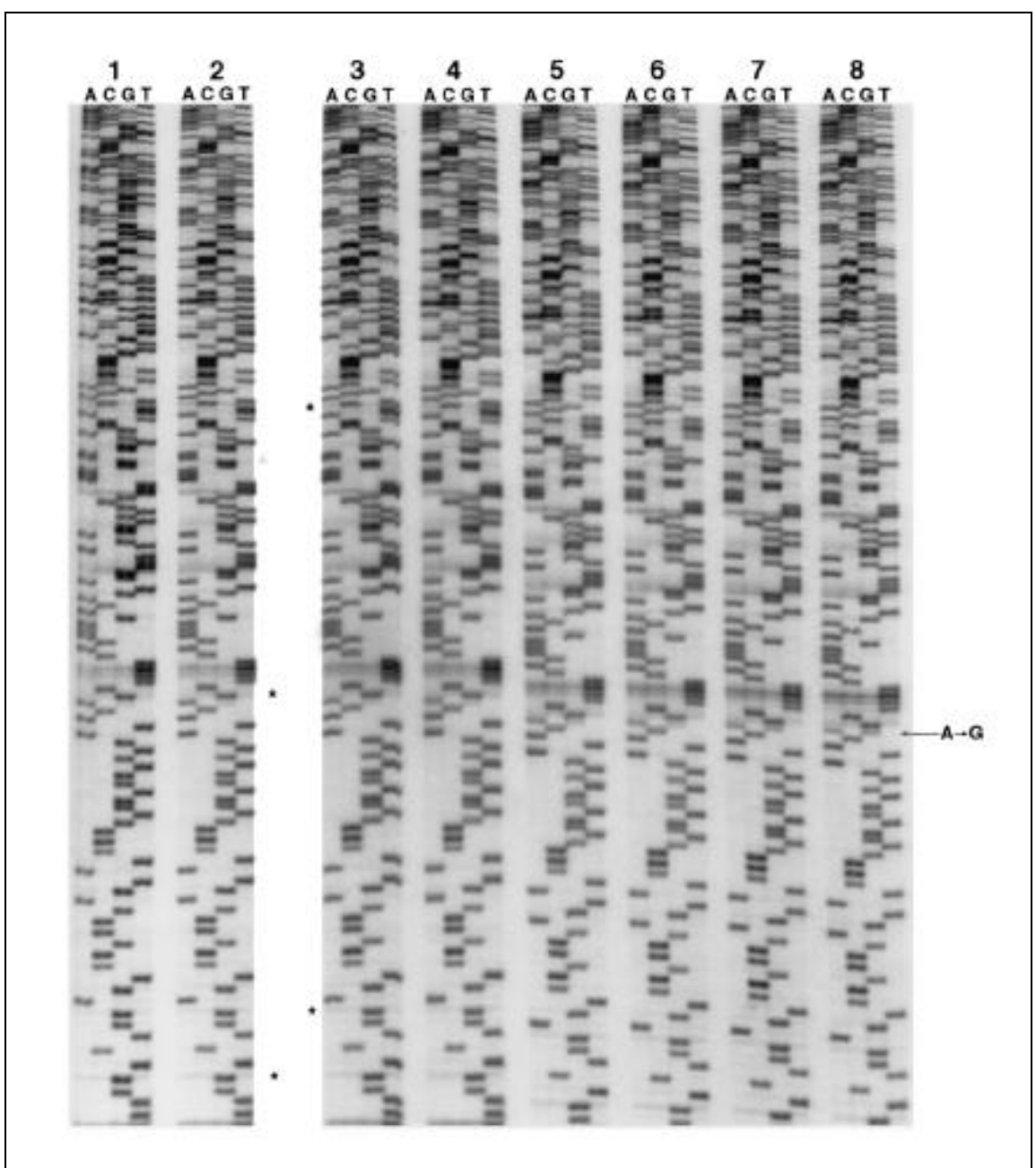

Figure 2. Sequencing autoradiogram of exon 6 of the p53 gene at different proportions of mutant and wild-type DNA. Lane 1: 10\% of mutant DNA; lane 2: 15\% of mutant DNA; lane 3: $20 \%$ of mutant DNA; lane 4: $25 \%$ of mutant DNA; lane 5: $30 \%$ of mutant DNA; lane 6: $35 \%$ of mutant DNA; lane 7: $40 \%$ of mutant DNA; lane 8: $50 \%$ of mutant DNA. used as molecular screening methods of mutation detection in several genes, such as p53 (4,5,8). Our analysis of samples with known proportions of mutant DNA confirms that DGGE has very high sensitivity. Indeed, samples containing as little as $10 \%$ of mutant DNA were scored as mutants by this technique. In contrast, direct sequencing of a PCR product requires $35 \%-$ $40 \%$ of mutant DNA, which corresponds approximately to a proportion of 70\%-80\% heterozygous mutant cells in tumor samples. Andersen and Børresen (1) provided experimental evidence for the hypothesis mentioned above, although they only compared two extreme proportions of mutant DNA (10\% and 50\%). We state precisely these results using a range of proportions with more intermediate points, finding that the lower limit of detection is approximately $35 \%$ or $40 \%$.

This is unlikely to represent the actual limit of detection under less stringent conditions. For instance, if automatic sequencing systems are implemented, it is unlikely that the degree of attention given to each sample would be comparable to the one given here. Furthermore, in this study, we have used different methods of sequencing (manual, automatic and cycle sequencing) and optimized the best resolution and minimal background conditions to obtain the highest sensitivity (cycle sequencing, reaction conditions, isotope, electrophoresis and exposure time for the particular fragment). All of these conditions are not usually met in routine analysis of tumor samples.

In spite of the fact that isotopic detection is generally considered much more sensitive than ethidium bromide staining, our results suggest that the sensitivity of DGGE for mutation detection is greater than sequencing for analysis of tumor samples. This apparent paradox might be explained considering the proportion of mutant DNA present in these samples and the mechanism of PCR amplification. This reaction is exponential so that both DNAs (wild-type and mutant) reach the limit of detection with ethidium bromide and can be visualized by DGGE. However, the small aliquot taken for cycle sequencing follows a linear amplification, so the low proportion of mutant DNA 
obtained makes the mutant band practically indistinguishable by autoradiography.

In conclusion, since clinical tumor specimens may frequently contain a large amount of stromal and inflammatory cells, and not all tumor cells may harbor gene mutation, direct sequencing may produce false-negative results because of the low proportion of mutant DNA in the samples. This needs to be considered when using direct PCR product sequencing as the only method of detection of mutations in DNA from tumor tissues. DNA sequencing remains the technique of choice to characterize mutations previously detected by mobility shift analysis.

\section{REFERENCES}

1.Andersen, T.I. and A.L. Børresen. 1995. Alterations of the TP53 gene as a potential prognostic marker in breast carcinomas. Diagn. Mol. Pathol. 4:203-211.

2.Andersen, T.I., R. Holm, J.M. Nesland, K.R. Heimdal, L. Ottestad and A.L. Børresen. 1993. Prognostic significance of TP53 alterations in breast carcinoma. Br. J. Cancer 68:540-548

3.Beck, J.S., A.E. Kwitek, P.H. Cogen, A.K. Metzger, G.M. Duyk and W.C. Sheffield. 1993. A denaturing gradient gel electrophoresis assay for sensitive detection of p53 mutations. Hum. Genet. 91:25-30.

4.Børresen, A.L., T.I. Andersen, J. Garber, N. Barbier-Piraux, S. Thorlacius, J. Eyfjörd, L. Ottestad, B. Smith-Sørensen et al. 1992. Screening for germ line TP53 mutations in breast cancer patients. Cancer Res. 52:32343236.

5.Børresen, A.L., E. Hovig, B. Smith-Sørensen, D. Malkin, S. Lystad, T.I. Andersen, J.M. Nesland, K.J. Isselbacher and S.H. Friend. 1991. Constant denaturant gel electrophoresis as a rapid screening technique for p53 mutations. Proc. Natl. Acad. Sci. USA 88:8405-8409.

6.Bosari, S. and G. Viale. 1995. The clinical significance of p53 aberrations in human tumors. Virchows Arch. 427:229-241.

7.Carbone, D., Y. Chiba and T. Mitsudomi. 1991. Polymorphism at codon 213 within the p53 gene. Oncogene 6:1691-1692.

8.Hamelin, R., N. Jego, P. Laurent-Puig, M. Vidaud and G. Thomas. 1993. Efficient screening of p53 mutations by denaturing gradient gel electrophoresis in colorectal tumor. Oncogene 8:2213-2220.

9.Loda, M.D. 1994. Polymerase chain reactionbased methods for the detection of mutations in oncogenes and tumor suppressor genes. Hum. Pathol. 25:564-571.

10.Lynch, H.T. 1981. Genetics and Breast Cancer. Van Nostrand Reinhold, New York.

11.Moyret, C., C. Theillet, P. Laurent-Puig, J.P. Molés, G. Thomas and R. Hamelin.
1994. Relative efficiency of denaturing gradient gel electrophoresis and single strand conformation polymorphism in the detection of mutations in exons 5 to 8 of the p53 gene. Oncogene 9:1739-1743.

12.Newmark, J.R., D.O. Hardy, D.C. Tonb, B.S. Carter, J.I. Epstein, W.B. Isaacs, T.R. Brown and E.R. Barrack. 1992. Androgen receptor gene mutations in human prostate cancer. Proc. Natl. Acad. Sci. USA 89:63196323.

The authors wish to thank M.J. Larrayoz for her enthusiastic and patient work and Dr. R. Hamelin, from Laboratoire de Genètique de Tumors de l'Institute Curie de Paris for his kindly providing us with the mutant control DNA. We also wish to thank Drs. F.J. Novo and F. Borrás for their invaluable comments on reading the manuscript and Drs. C. De Miguel and L.A. Pérez-Mediavilla for their help in blind reading of autoradiograms. Address correspondence to M. García-Delgado, Department of Genetics, Faculty of Science, University of Navarra, Pamplona (Navarra) E-31080, Spain.

Received 30 January 1997; accepted 17 July 1997.

M. García-Delgado, C.J. González-Navarro, M.C. Napal, C. Baldonado, J.L. Vizmanos and A. Gullón University of Navarra Pamplona, Spain

\section{Defogging Tissue Culture Lids for Viewing Cells}

BioTechniques 24:76 (January 1998)

Most cell or tissue culture labs require an inexpensive, effective method of defogging culture chamber lids. Our solution is a travel-size hairdryer (for example, Conair ${ }^{\circledR}$ Pro Baby ${ }^{\mathrm{TM}}$ 1250) clamped onto a ringstand. The hairdryer costs about $\$ 15$, and every laboratory has ringstands abandoned in corners. We angled the hairdryer at $45^{\circ} \mathrm{C}$ so that airflow is not forced under the culture chamber lids. The distance between the dryer and the lid is 8 in, and the temperature of the air striking the lid is $45^{\circ} \mathrm{C}$ when the heat setting is lowest. Since plastic lids are poor heat conductors, the temperature at the bottom of the culture chamber does not increase in the 10-15 min needed to examine multiple wells in a plate.

We examined the growth and differentiation characteristics of several mammalian cell types, including monkey kidney epithelial cells (COS-1) and a rodent skeletal muscle cell line (C2C12) (both from ATCC, Rockville, MD, USA) as well as mouse embryonic stem cells (a kind gift of Allen Bradley, Baylor College of Medicine) after defogging for up to $15 \mathrm{~min}$ daily for three weeks. All cells grew and differentiated indistinguishably from those in non-defogged chambers. Cells examined this way were cultured in different-sized tissue culture dishes, chamber slides and multi-well culture plates. The cell culture media contained up to $10 \%$ serum and two antibacterial agents, $100 \mu \mathrm{g}$ streptomycin $/ \mathrm{mL}$ and $100 \mathrm{U}$ of penicillin $/ \mathrm{mL}$. Antifungal agents were not used. We have used the hairdryer method of defogging for a year without causing bacterial or fungal contamination.

Our inexpensive, benign method of defogging culture lids has allowed us to do video- and photomicroscopy on up to six wells at one sitting. We recommend this technical improvement.

This work was supported by a Neuromuscular Disease Research Grant from the Muscular Dystrophy Association and a grant from the John F. Smiekel Foundation, both to M.G.P. We thank Dr. Hugo Bellen for the loan of the inverted microscope. Address correspondence to Maureen G. Price, Department of Biochemistry and Cell Biology, MS 140, Rice University, Houston, TX 77251-1892, USA. Internet: maureen@ bioc.rice.edu

Received 19 May 1997; accepted 30 May 1997.

Maureen G. Price, Jeanette M. Schwartz Ebarb and Edward

G. Frank

Rice University

Houston, TX, USA 